\title{
Rearrangement of the 5S Ribosomal RNA Gene Clusters During the Development and Replication of the Macronucleus in Tetrahymena thermophila
}

\author{
Sally Lyman Allen, Paul R. Ervin, Theodore C. White, and Ning C. McLaren \\ Division of Biological Sciences, The University of Michigan, Ann Arbor
}

\begin{abstract}
The organization of the 5S rRNA genes in the MACronuclear genome of Tetrahymena thermophila was examined during MAC development and replication. The $5 \mathrm{~S}$ genes are arranged in several tandem arrays of alternating transcribed and spacer sequences in both MICronucleus and MAC. The number of EcoRI fragments bearing $5 S$ gene clusters is similar in MIC and MAC. Most fragments occur in both the MIC and newly formed MAC genomes, a few being MIC-limited and a few MAC-limited. The same rearrangements are seen in the MACs of all four caryonides of a mating pair, and most rearrangements are seen in the newly formed MACs of different inbred strains. During replication of the MAC about half the fragments bearing $5 S$ gene clusters disappear in different cell lines, and new fragments containing $5 S$ genes appear. These fragments differ in size from those present in the MIC or newly formed MAC. These alterations occur in the MACs of all strains except strain $B$, which is more resistant to vegetative rearrangement. The losses and gains of fragments occur during clonal propagation of cell lines. The process begins by 35 fissions following conjugation, but once an alteration occurs, it is stably propagated. Clonal variation occurs with respect to which losses and gains occur, although a nonrandom distribution is seen among cell clones. We conclude that the alterations in MAC fragment size occur at two stages in the life cycle of Tetrahymena. The first stage occurs during conjugation, when the MAC develops from the MIC. The second stage becomes manifest during vegetative growth, when DNA replication occurs in the MAC and daughter molecules are distributed "amitotically" to daughter nuclei. The two-stage character to MAC alterations for the $5 S$ genes is interpreted in terms of the two steps previously described for MAC differentiation: determination and phenotypic assortment. Possible molecular mechanisms are also discussed.
\end{abstract}

Key words: 5S ribosomal RNA genes, rearrangement, macronuclear development, macronuclear replication, Tetrahymena thermophila, determination, phenotypic assortment

\section{INTRODUCTION}

The problem of nuclear differentiation has been a key issue in eukaryotic organisms with regard to totipotency in supporting normal development. Until re-

Received for publication July 25, 1984; accepted January 22, 1985.

Address reprint requests to Dr. Sally L. Allen, Division of Biological Sciences, The University of Michigan, Ann Arbor, MI 48109. 
cently, the only well-documented case of irreversible nuclear differentiation concerned the formation of the macronucleus (MAC) in the ciliated protozoa. With the gene cloning techniques it has become apparent that rearrangements of DNA are not unusual in eukaryotes. For example, segments of DNA are brought together by splicing during the developmental regulation of immunoglobulin class switching [1]. Or, DNA segments move from one region to another as is the case when yeast mating types interconvert [2], or a switch in the expression of antigen genes occurs in trypanosomes [3]. Moreover, a growing number of potential moveable elements have been identified, such as the alu repeated sequence family, which shows polymorphism in different tissues in humans [4].

Like other ciliated protozoa, Tetrahymena thermophila has two kinds of nuclei coexisting in a common cytoplasm. The MAC develops from a product of the micronucleus (MIC) following meiosis during normal conjugation. During development of the MAC, the DNA content is replicated to a value 23-32 times that of the MIC, the chromosomes fragment, some sequences are underreplicated, some are deleted, some are overreplicated, and other sequences are rearranged [5-11]. The ability to transcribe is acquired following alterations in chromatin composition which accompany the genomic changes [12].

Further changes in DNA content and genomic make up of the MAC occur during vegetative growth. Genes which are expressed in heterozygotes undergo phenotypic (allelic) assortment in which sublines are produced which express one or the other of the alleles [13]. The number of assorting units is 45 in a mature G1 MAC. The DNA content at this time is sufficient for 45 copies of each gene, implying that the assorting units are haploid. The mature MAC is, therefore, a highly differentiated somatic nucleus, which has become irreversibly altered during development and vegetative growth.

The MAC is destroyed during normal conjugation, and two new ones are generated from the germinal MIC in each conjugant. At the first postzygotic cell division the two new MACs segregate without division to the daughter cells. The clones derived from the first postzygotic daughters are called caryonides. A set of four caryonides is produced from one mating pair, each cell with an independently differentiated new MAC.

The organization of the 5S rRNA genes in the MIC of Tetrahymena is similar to that of other eukaryotes, such as Drosophila or Xenopus, in that the several hundred genes are arranged in tandem arrays of alternating transcribed and spacer sequences, and they are unlinked to the larger species of rRNA genes (14-16). Each repeating unit appears to be approximately 280 base pairs in length, consisting of a 120 base pair gene and a 160 base pair AT-rich spacer region [15].

Despite the similarity in organization, the chromosomal distribution of the $5 \mathrm{~S}$ genes in Tetrahymena differs from Drosophila or Xenopus [17]. As found for Neurospora [18], the genes are dispersed. Clusters of two to ten or 20 gene copies are found on 32 EcoRI fragments, $2 \mathrm{~kb}$ or larger, in the MIC. These MIC clusters are dispersed on chromosomes $1,3,4$, and 5, with 17 of the clusters located on chromosome 1. A crude deletion map could be constructed that groups the clusters to various segments of chromosome 1, with four groups of clusters being placed on the right arm. None of the $5 \mathrm{~S}$ genes were found to be linked to the 17-26S rRNA genes found at the $r d n A$ locus on chromosome $2[17,19]$. 
The pattern of EcoRI fragments with $5 \mathrm{~S}$ gene clusters is very similar in the MICs of different inbred strains [17]. This observation indicates that the 5S rRNA genes are conserved in their organization in the $T$ thermophila genome. The few differences seen in the various genomes reflect the origins of the strains and thus may be genetic.

The number of EcoRI fragments bearing $5 \mathrm{~S}$ gene clusters was found to be similar in MIC and MAC $[15,17]$. Most clusters are found in both the MIC and MAC genomes, a few being MIC-limited and a few MAC-limited [15,17]. During MAC development only minimal reorganization of the $5 \mathrm{~S}$ genes occurs, the pattern of reorganization being conserved in different strains [17]. However, the number of copies of the $5 \mathrm{~S}$ genes appears to increase by one-third [17]. This paper focuses on our observations on the changes that occur in the 5S rRNA gene clusters not only during the development of the MAC but also in vegetative growth.

\section{MATERIALS AND METHODS Cell Lines}

Three types of cell lines were derived from a cross of $T$ thermophila inbred strain D (D-25772a) and its congenic strain D/1 (D/1-5771) (Fig. 1). Strain D/1 or $\left(I_{1}\right)$ was obtained by outcrossing strain $D$ to strain $C 2$, with selection of certain $C 2$ genes during 12 successive backcrosses to $D$, followed by genomic exclusion [20]. One type of cell line was a population of recently conjugated cells from a population of exconjugants purified by the use of magnetic columns [21] and is referred to as the MAC population. Another type of cell line included two sets of caryonides isolated

$$
D \times D / I(I)
$$

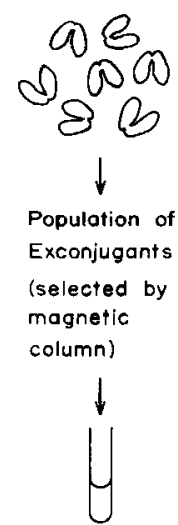

Population

of Recently

Conjugated

Cel/s

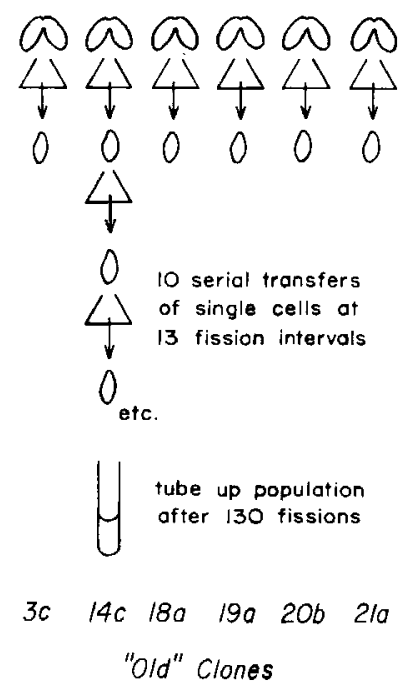

Fig. 1. Derivation of various cell lines from the $D \times D / 1(1)$ cross. 
from two different mating pairs. The third type of cell line included six cell lines referred to as the "old cell clones." These originated from cross A75-163, in which single cells were isolated from the progeny of individual pairs at 13 fissions following conjugation, with recloning at 13 fission intervals up to 130 fissions. These lines were subcultured bimonthly (1976-1978) or monthly (1979-1985) so that they are now about 1,000 fissions old.

Additional subcloning was carried out. The caryonides were serially subcloned at 35,75 , and 115 fissions. The old cell clones were subcloned from tubed populations when they were about $900-1,000$ fissions old.

In addition to the $\mathrm{D} \times \mathrm{D} / 1$ cell lines we examined the following clones from inbred strains A, B, C2, C3, D, and D/1: A-17686, B-2079X2, B-2079X6, B-18684b, B-18684, B-18687N, B-18687B, C2-3686, C2-3686c, C2-4683, C3-3685, D-25771, D-25776, D-25773, D-25772, D-25771a, D-25772a (ATCC 30845), and D/1( $\left.\mathrm{I}_{1}\right) 5771$ (ATCC 30847). All the 1968 clones are about 2,000 fissions old except for B-18684 and B-18687N, which were frozen until 1973-1974. D-25772a and D/1-5771 were frozen at the American Type Culture Collection, and are about 100-150 fissions old. The other 1977 D-strain clones were not frozen and are about 400-500 fissions old. The origin and relationship of the inbred strains is detailed in reference 17. Subclones were isolated from B-18687B and C3-3685.

\section{Growth of Cultures}

For nuclear preparations, test-tube cultures were grown in $1 \%$ proteose-peptone for 2 days at $30^{\circ} \mathrm{C}$. Flasks containing PP2 10 medium (2\% proteose-peptone, $10 \mu \mathrm{M}$ $\mathrm{FeCl}_{3}$ ) were inoculated with test-tube cultures, grown for 24 hours in a shaker water bath at $30^{\circ} \mathrm{C}$, and the cell concentration determined. Five-liter diptheria toxin bottles containing $3 \mathrm{~L}$ of PP210,3 ml of antifoam B (Baker), and penicillin-streptomycin $(250 \mu \mathrm{g} / \mathrm{ml})$ were inoculated with an aliquot of cells sufficient to give a final concentration of 2-3 $\times 10^{5}$ cells $/ \mathrm{ml}$ after growth at $30^{\circ} \mathrm{C}$ with gentle aeration in a large water bath.

\section{Nuclear Isolation and DNA Preparation}

Nuclei were isolated using the Percoll gradient method [22]. MAC and MIC DNA was isolated by $\mathrm{CsCl}$ gradient centrifugation, following the procedure outlined elsewhere [22]. MAC DNA was used only if it contained less than 1 MIC in 200 MAC. This level of purity was easily obtained and insured that any slight contamination by MIC would be less than what our system could detect. The purification of MAC involved collecting, concentrating, and homogenizing the cells, low-speed centrifugation (769 g), addition of NP40 (Nonidet P40; Shell Chemicals) to a concentration of $0.2 \%$, and repeated Percoll gradient centrifugation until the nuclei reached the desired purity.

\section{Hybridization Probe}

Plasmid pDP5, obtained from D. Pederson (University of Rochester), contains a 280-bp BamHI fragment of a MIC 5S rRNA gene plus AT-rich spacer cloned into the BamHI site of pBR322 [23]. DNA from this plasmid was used to transform E coli strain HB101. Plasmid DNA was isolated by a modification of the SDS/high salt 
cleared lysate procedure [24] followed by $\mathrm{CsCl} / \mathrm{ethidium}$ bromide gradient centrifugation in a vertical rotor, and the DNA was labeled in vitro with $\alpha^{32} \mathrm{P}$ to $1 \times 10^{8}$ $\mathrm{cpm} / \mu \mathrm{g}$ by a modified nick translation procedure $[25,26]$.

\section{Restriction Endonuclease Digestion, Gel Electrophoresis, and Southern Blots}

In most experiments the restriction enzyme EcoRI was used to digest nuclear DNA. In a few experiments the restriction enzymes Xba I, Bgl II, or Hind III, which also do not cut within the $5 S$ gene cluster, were used. For each enzyme, digestion of DNA was carried out according to the directions given by the supplier of the enzymes, Bethesda Research Laboratories. Five to six micrograms of DNA was digested per reaction mixture in a total volume of $20 \mu \mathrm{l}$. Two units of enzyme were used per microgram of DNA, and digestion was carried out overnight to ensure complete digestion. The DNA was heat-shocked to prevent reannealing of the ends before loading into wells in agarose gels. To monitor visually electrophoresis, bromphenyl blue dye was added to the reaction mixture just before electrophoresis. The gels used were $0.6 \%$ agarose in Tris-borate buffer containing ethidium bromide, poured into plates for a 12-inch-long 6-inch-wide submarine gel. The maximum capacity of the wells was $50 \mu \mathrm{l}$. Electrophoresis of the DNA was carried out for 60 hours at $10 \mathrm{~mA}$ or until the Hind III digested lambda marker, which contains a 1.96-kb fragment, was 1 inch from the end of the gel.

After electrophoresis the gels were irradiated for 10 minutes with a broad spectrum UV lamp. During this time the DNA was visualized and the distances traversed by the marker fragments measured. The gels were then prepared for transfer of the DNA to nitrocellulose filters (Schleicher and Schuell) using the method of Southern [27] with modifications. For the preparative washings of the gel prior to Southern blotting, each gel was kept on the plate used for electrophoresis to prevent distortion due to its low agarose concentration. The length of the time of these washes was extended in proportion to the size of the gel.

\section{Hybridization and Autoradiography}

After the filters were baked for 1.5 hours at $80^{\circ} \mathrm{C}$, they were loaded into sealable bags (Hamilton Beach), soaked for 0.5 hour at $62^{\circ} \mathrm{C}$ in $3 \times \mathrm{SSC}$ (SSC = $0.15 \mathrm{M}$ sodium chloride, $0.015 \mathrm{M}$ sodium citrate, $\mathrm{pH} 7.0$ ), and prehybridized for $3-5$ hours at $62^{\circ} \mathrm{C}$ in $10 \times$ Denhardt's solution [28], $3 \times \mathrm{SSC}, 0.1 \% \mathrm{SDS}$, and $25 \mu \mathrm{g} / \mathrm{ml}$ of denatured carrier (calf thymus) DNA. Filters were hybridized for 36 hours at $62^{\circ} \mathrm{C}$ immediately following prehybridization. The hybridization solution contained fresh prehybridization mixture with the addition of the nick translated probe $\left(6 \times 10^{7}\right.$ cpm).

The hybridization filters were washed four times in $2 \times$ SSC containing $1 \%$ SDS for 30 minutes at $65^{\circ} \mathrm{C}$. They were then washed once in $0.2 \times \mathrm{SSC}$ containing $1 \%$ SDS for 30 minutes, then once in $2 \times \mathrm{SSC}$ for 10 minutes, both at $65^{\circ} \mathrm{C}$. The filters were dried for 2 hours and exposed to Kodak XAR-5 film at $-80^{\circ} \mathrm{C}$ with an intensifying screen for 1-10 days, depending on the radioactivity of the filter following the washes. Several exposures were made for each filter to obtain optimum band crispness. 


\section{RESULTS}

\section{Hybrid Strain D $\times$ D/1 (DI)}

During development of the MAC, the total number of EcoRI fragments with $5 \mathrm{~S}$ gene clusters remains about the same but there is a slight increase in the kb total. The restriction enzyme EcoRI does not appear to cut within the $5 \mathrm{~S}$ gene repeats, but outside the cluster. Thus, after digesting DNA with EcoRI, electrophoresis, blotting, and probing with a 5S rRNA probe, the banding patterns represent the clusters of the 5S rRNA genes accompanied by their flanking regions. This means, then, that there is a 1:1 correspondence between the number of clusters and number of fragments, barring sequence heterogeneity between clusters. A total of 32 fragments (clusters) ranging in size from 24 to $2 \mathrm{~kb}$ (bottom of gel) is observed in the MIC, while 34 fragments (clusters) ranging in size from 30 to $2 \mathrm{~kb}$ are seen in the MAC from the population of recently conjugated cells. The total $\mathrm{kb}$ of fragments with 5S gene clusters along with their flanking sequences is 263 for the MIC and 319 for the MAC (Table 1).

Twenty-seven fragments bearing $5 \mathrm{~S}$ gene clusters are found in both MIC and MAC (demarked by arrowheads in Fig. 2). Five fragments (2.2, 3.05, 8.8, 9.0, and $24.0 \mathrm{~kb})$ are limited to the MIC; seven fragments $(5.8,6.1,6.7,7.1,19.6,28.0$, and $30.0 \mathrm{~kb}$ ) are limited to the MAC from the population of recently conjugated cells. Additional MAC-limited fragments $(9.7,9.2$, and $6.9 \mathrm{~kb})$ are visible in the MAC of caryonides (Table 1). Hence, the majority of the clusters are found on fragments of identical size in both MIC and newly formed MAC. However, for 16 of the 27 fragments found in common, the MAC cluster appeared to contain a slightly greater number of repeats than the corresponding MIC cluster, determined by integrating densitometric tracings made from autoradiograms [17]. Using similar amounts of DNA in the gels, the total number of $5 S$ gene copies in the newly formed MAC was

TABLE 1. Fragments With $5 S$ Gene Clusters in the Developing MAC of $D \times D / 1$

\begin{tabular}{|c|c|c|c|c|c|c|c|c|c|c|c|c|}
\hline \multirow[b]{3}{*}{$\begin{array}{l}\text { Source } \\
\text { of DNA }\end{array}$} & \multirow[b]{3}{*}{$\begin{array}{l}\text { Total No. } \\
\text { fragments }\end{array}$} & \multirow[b]{3}{*}{$\begin{array}{c}\text { Total } \\
\mathrm{kb}\end{array}$} & \multicolumn{8}{|c|}{ Particular fragments } & \multicolumn{2}{|c|}{ No. of other fragments } \\
\hline & & & \multicolumn{3}{|c|}{$\begin{array}{l}\mathrm{MIC} / \mathrm{MAC} \\
\text { fragments }\end{array}$} & \multicolumn{5}{|c|}{ MAC-limited fragments } & \multirow[b]{2}{*}{$\begin{array}{c}\text { MIC/MAC } \\
\text { fragments }\end{array}$} & \multirow{2}{*}{$\begin{array}{c}\text { "Nuclear } \\
\text { limited } \\
\text { fragments" }\end{array}$} \\
\hline & & & $\frac{11}{10.5}$ & 4.7 & 4.65 & 9.7 & 9.2 & 7.1 & 6.9 & 6.1 & & \\
\hline MIC & 32 & 262.7 & + & $\mathrm{f}^{\mathrm{a}}$ & $?^{\mathrm{b}}$ & - & - & - & - & - & 25 & 5 \\
\hline $\begin{array}{l}\text { MAC } \\
\text { (population) }\end{array}$ & 34 & 319.0 & + & + & $?$ & $?$ & $?$ & + & $?$ & + & 25 & 5 \\
\hline \multicolumn{13}{|l|}{ Caryonides } \\
\hline $31 \mathrm{~A}$ & 36 & 335.1 & + & + & - & - & + & + & + & + & 25 & 5 \\
\hline B & 36 & 335.0 & + & - & + & - & + & + & + & + & 25 & 5 \\
\hline $\mathrm{C}$ & 37 & 339.7 & + & + & + & - & + & + & + & + & 25 & 5 \\
\hline $\mathrm{D}$ & 37 & 339.7 & + & + & + & - & + & + & + & + & 25 & 5 \\
\hline $42 \mathrm{~A}$ & 37 & 338.9 & - & + & + & + & + & + & + & f & 25 & 5 \\
\hline B & 36 & 334.2 & - & - & + & + & + & + & + & + & 25 & 5 \\
\hline C & 36 & 334.2 & - & - & + & + & + & + & + & f & 25 & 5 \\
\hline D & 37 & 338.9 & - & + & + & + & + & + & + & + & 25 & 5 \\
\hline Mean & 36.5 & 337.0 & & & & & & & & & & \\
\hline
\end{tabular}

${ }^{\text {aff, faint. }}$

b?, not observed, but expected (see caryonides).

${ }^{c}$ For the MIC, includes the 24-, 9-, 8.8-, 3.05-, and 2.2-kb fragments; for the MAC, includes the 30-, 28-, 19.6-, 6.7-, and 5.8-kb fragments. 


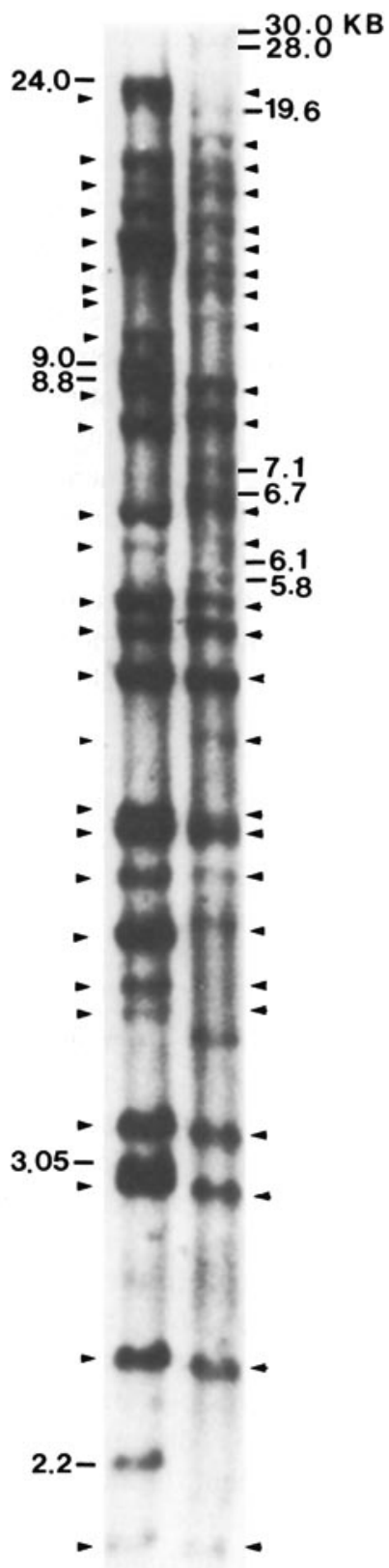

Fig. 2. Autoradiogram of Southern blot of DNA from the micronucleus (MIC) or macronucleus (MAC) obtained from a population of recently conjugated cells from a cross of $\mathrm{D} \times \mathrm{D} / 1$ (DI), probed with $\alpha^{32} \mathrm{P}$ labeled pDP5 (which contains one copy of the 5S DNA and spacer). Each DNA ( $5 \mu \mathrm{g} / \mathrm{lane}$ ) was digested with EcoRI. After electrophoresis in a $0.6 \%$ agarose submarine gel, 12 inches long, for 60 hours at 10 $\mathrm{mA}$, it was blotted to nitrocellulose. Fragments that are MIC-limited $(24.0,9.0,8.8,3.05,2.2 \mathrm{~kb}) \mathrm{or}$ MAC-limited (30.0, 28.0, 19.6, 7.1, 6.7, 6.1, $5.8 \mathrm{~kb})$ are indicated by their size in kilobases (kb). Additional MAC-limited fragments $(9.7,9.2,6.9 \mathrm{~kb})$ are seen in the MAC of caryonides. Arrowheads point to the 27 fragments common to $\mathrm{MIC}$ and $\mathrm{MAC}(21.8,18.0,17.2,16.0,14.3,12.5,11.5,10.5$, $9.5,8.1,7.6,6.6,6.5,5.7,5.5,5.1,4.7,4.35,4.3,4.1,3.9,3.7,3.6,3.2,2.95,2.45$, and $2.0 \mathrm{~kb}$ ). The $4.7-\mathrm{kb}$ fragment is normally very faint in the MIC of DI. 
found to be one-third greater than in the MIC [17]. A similar number of gene copies was found in both MIC and MAC by Pederson et al [23].

For the changes that occur, during development of the MAC, the process is controlled since the array of fragments bearing the $5 \mathrm{~S}$ gene clusters is the same in the MACs of all four caryonides from single mating pairs. If DNA alterations occurred in a random fashion during formation of the MAC from its MIC precursor, we might expect differences in the pattern of fragments containing $5 \mathrm{~S}$ gene clusters between MACs which have developed independently. By examining the four caryonides from a single mating pair, this assessment can be made since each caryonide has an independently differentiated new MAC.

The data from two sets of caryonides from a $D \times D / 1$ mating are shown in Table 1. All four caryonides of a set show identity in their pattern except for the 4.7and 4.65-kb fragments. Although 27-28 fragments containing $5 \mathrm{~S}$ gene clusters are found in both MIC and MAC, ten fragments appear to have been generated during MAC development, since they are limited to the MAC. Only one difference was seen between the two sets of caryonides: the 31 set retained a $10.5-\mathrm{kb}$ fragment found in the MIC and in many MACs, while this fragment disappeared in the 42 set and a new fragment $(9.7 \mathrm{~kb})$ was seen in the MACs of all four caryonides of this set. These observations suggest that, despite the fact that most $5 \mathrm{~S}$ gene clusters are not rearranged during development of the MAC, where changes occur, they are highly repeatable in all MACs - and are not random events. This implies that the process leading to these changes is highly controlled.

Two fragments $(4.7,4.65 \mathrm{~kb})$ show variability among the caryonides of both sets. Either both fragments are present, or one or the other fragment is present in a caryonide. Sister caryonides, which contain MACs derived from the same exconjugant, are, however, not necessarily alike in their pattern. This observation implies independence in the behavior of these two fragments within a developing MAC. The fact that both fragments are present in four out of eight caryonides, and that one or the other fragment is present in the other four, suggests that these two fragments may be "allelic" and are showing phenotypic assortment.

After vegetative replication of the MAC, certain fragments bearing $5 S$ gene clusters disappear (are "lost"), and other fragments not seen before appear (are "gained"). In contrast to the uniformity in caryonidal $5 \mathrm{~S}$ gene pattern, variability in pattern was observed when cell cloning of the hybrid strain $D \times D / 1$ was carried out 130 fissions following conjugation and the clones were sampled about 1,000 fissions later. As shown in Figure 3, two types of variability are seen in the gels of six old cell clones. Particular fragments have disappeared from one or more of the cell clones; for example, the 3.2-kb fragment, found in the MIC and newly formed MAC, is observed in $14 c, 18 a$, and $20 b$, but is not seen in 3c, 19a, and 21a. Other fragments, not present in the MICs and MACs of caryonides have appeared, such as the $2.65-\mathrm{kb}$ fragment seen in 3c, 19a, 20b, and 21a. A similar degree of variability in pattern was seen between cell clones after digesting MAC DNA with other restriction endonucleases such as Xba I, Bgl II, or Hind III that cut outside the cluster.

The losses and gains of EcoRI fragments seen in the MACs of the old cell clones and three sets of their subclones are compared to newly formed MACs using caryonide $31 \mathrm{~A}$ as reference (Table 2). The total number of fragments with $5 \mathrm{~S}$ gene clusters and their total $\mathrm{kb}$ are given in the second and third columns. Note that these figures decrease in the old cell clones. A mean number of 31.75 fragments totalling $298.9 \mathrm{~kb}$ 


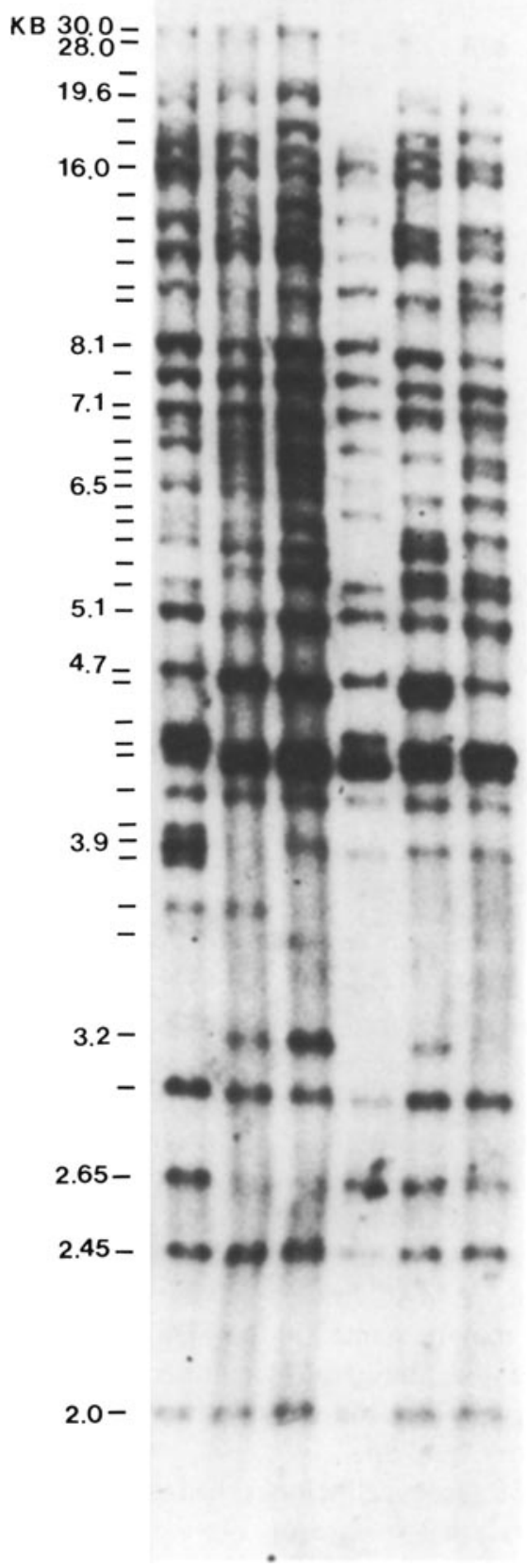

Fig. 3. Autoradiogram of Southern blot of DNA from the macronucleus of the six D $\times D / 1$ old cell lines probed with $\alpha^{32} \mathrm{P}$-labeled pDP5 (which contains one copy of the 5S DNA and spacer). Each DNA ( $5 \mu \mathrm{g} /$ lane) was digested with EcoRI. After electrophoresis in an $0.6 \%$ agarose submarine gel, 12 inches long, for 60 hours at $10 \mathrm{~mA}$, it was blotted to nitrocellulose. The sizes of some of the fragments in kilobases (kb) are indicated to the left of the gel. 
TABLE 2. Fragments With $5 S$ Gene Clusters in the MAC After Vegetative Replication of $D \times D / 1$

\begin{tabular}{|c|c|c|c|c|c|c|c|c|c|c|c|c|c|}
\hline \multirow{3}{*}{$\begin{array}{l}\text { Source } \\
\text { of DNA }\end{array}$} & \multirow{3}{*}{$\begin{array}{l}\text { Total No. } \\
\text { fragments }\end{array}$} & \multirow{3}{*}{$\begin{array}{c}\text { Total } \\
\mathrm{kb}\end{array}$} & \multicolumn{8}{|c|}{ Particular fragments } & \multicolumn{3}{|c|}{ No. of remaining fragments ${ }^{a}$} \\
\hline & & & \multicolumn{3}{|c|}{$\begin{array}{l}\mathrm{MIC} / \mathrm{MAC} \\
\text { fragments }\end{array}$} & \multicolumn{5}{|c|}{ MAC-limited fragments } & \multirow{2}{*}{$\begin{array}{l}\text { MIC/MAC } \\
\text { fragments }\end{array}$} & \multirow{2}{*}{$\begin{array}{c}\text { MAC- } \\
\text { limited } \\
\text { fragments }\end{array}$} & \multirow{2}{*}{$\begin{array}{c}\text { MAC fragments } \\
\text { gained } \\
\text { during aging }\end{array}$} \\
\hline & & & 10.5 & 4.7 & 4.65 & 9.7 & 9.2 & 7.1 & 6.9 & 6.1 & & & \\
\hline \multicolumn{14}{|l|}{ Caryonide } \\
\hline $31 \mathrm{~A}$ & 36 & 335.1 & + & + & - & - & + & + & + & + & 25 & $5^{\mathrm{c}}$ & $\mathbf{0}$ \\
\hline \multicolumn{14}{|c|}{ Old cell clones and their subclones ${ }^{b}$} \\
\hline $3 c-1$ & 34 & 310.2 & - & + & - & - & - & + & - & + & 21 & 5 & 5 \\
\hline $3 c-2$ & 31 & 297.7 & - & + & - & - & - & + & - & + & 20 & 5 & 3 \\
\hline $3 c-2 a$ & 31 & 298.2 & - & + & - & - & - & + & - & - & 21 & 5 & 3 \\
\hline $3 c-2 b$ & 31 & 298.2 & - & + & - & - & - & + & - & - & 21 & 5 & 3 \\
\hline $3 c-2 c$ & 31 & 298.2 & - & + & - & - & - & + & - & - & 21 & 5 & 3 \\
\hline $14 \mathrm{c}$ & 34 & 313.6 & + & - & + & - & + & + & + & - & 23 & 5 & 1 \\
\hline $18 a$ & 35 & 328.7 & + & - & + & - & - & + & + & + & 24 & 5 & 1 \\
\hline $19 a-1$ & 30 & 281.2 & + & + & - & - & - & + & - & + & 17 & $3^{d}$ & 6 \\
\hline $19 a-2$ & 30 & 281.2 & + & + & - & - & - & + & - & + & 17 & 3 & 6 \\
\hline $19 a-2 a$ & 29 & 270.7 & - & + & - & - & - & + & - & + & 17 & 3 & 6 \\
\hline $19 a-2 b$ & 29 & 270.7 & - & + & - & - & - & + & - & + & 17 & 3 & 6 \\
\hline $19 a-2 c$ & 29 & 270.7 & - & + & - & - & - & + & - & + & 17 & 3 & 6 \\
\hline $20 \mathrm{~b}$ & 32 & 289.2 & - & - & + & - & - & - & + & - & 23 & 5 & 2 \\
\hline 21a & 35 & 329.3 & - & + & - & + & + & + & + & - & 22 & $4^{\mathrm{e}}$ & 4 \\
\hline 2la-1 & 34 & 325.6 & - & + & - & + & + & + & + & - & 21 & 4 & 4 \\
\hline $21 a-2$ & 33 & 317.5 & - & + & - & + & + & + & + & - & 20 & 4 & 4 \\
\hline Mean & 31.75 & 298.8 & & & & & & & & & & & \\
\hline
\end{tabular}

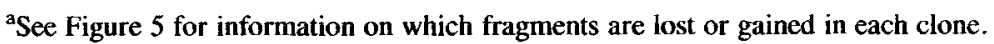

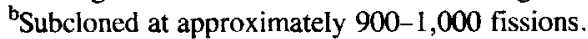

Includes the MAC-limited 30-, 28-, 19.6-, 6.7-, and 5.8-kb fragments.

${ }^{\mathrm{d}}$ Missing the MAC-limited 19.6- and 5.8-kb fragments.

'Missing the MAC-limited 19.6-kb fragment.

is seen compared to 36 fragments totalling $335.1 \mathrm{~kb}$ in caryonide $31 \mathrm{~A}$. In the columns to the right of Table 2 are two categories of fragments: those identified individually by their kb and those identified only by total number in a group. Of those specifically identified by their $\mathrm{kb}$, three are MIC/MAC fragments and five are MAC-limited fragments. Of those identified only by numbers in a group, there are three groups: the MIC/MAC group, a MAC-limited group, and a group of new fragments gained during vegetative replication. Fragments with clusters that are common to MIC and MAC as well as those that are MAC-limited may be lost, and one to six new fragments bearing $5 \mathrm{~S}$ gene clusters may be gained in the MAC. The least number of alterations is seen in clones $14 \mathrm{c}$ and $18 \mathrm{a}$, the greatest number in clone 19a. Although we have looked for a relationship between the sizes of new and old fragments, we have not been able to make the sizes "add up."

Samples of each of these cell clones had been maintained as two separate cultures for over 3 years. In the case of 19a-1 and 19a-2 identity in pattern was observed, but in the case of $3 c-1$ and $3 c-2$ differences were observed. Four fragments found in 3c-1 were absent from 3c-2, and one fragment present in 3c-2 was not visible in $3 c-1$. Subcloning was carried out on $3 c-2,19 a-2$, and one of the lines of $21 a$. All three $3 c-2$ subclones were identical in pattern to each other but differed in two fragments from $3 \mathrm{c}-2$ (absence of 6.1-kb fragment, presence of 6.6-kb fragment). All 
three 19a-2 subclones were similar to each other but lacked the 10.5-kb fragment found in both 19a-1 and 2. The two 21a subclones differed from each other in a single fragment (an 8.1-kb fragment present in 21a-1 but absent from 21a-2). They both differed from 21a in the absence of a second fragment $(3.7 \mathrm{~kb})$.

These results were surprising since they suggested change in the fragment pattern of $5 \mathrm{~S}$ gene clusters occurring as a function of macronuclear replication. Since the cell lines were about 1,000 fissions old, we might be observing the accumulation of vegetative alterations that have occurred during prolonged culture. Might we see such alterations after fewer fissions following conjugation?

When caryonides are serially cloned, the loss and gain of fragments with 5S gene clusters is detectable by 35 fissions. The design of this experiment is illustrated in Figure 4. Three of the four caryonides from the 31 set (A,B, and D) were cloned at particular fission intervals. At each time point three, or more, single

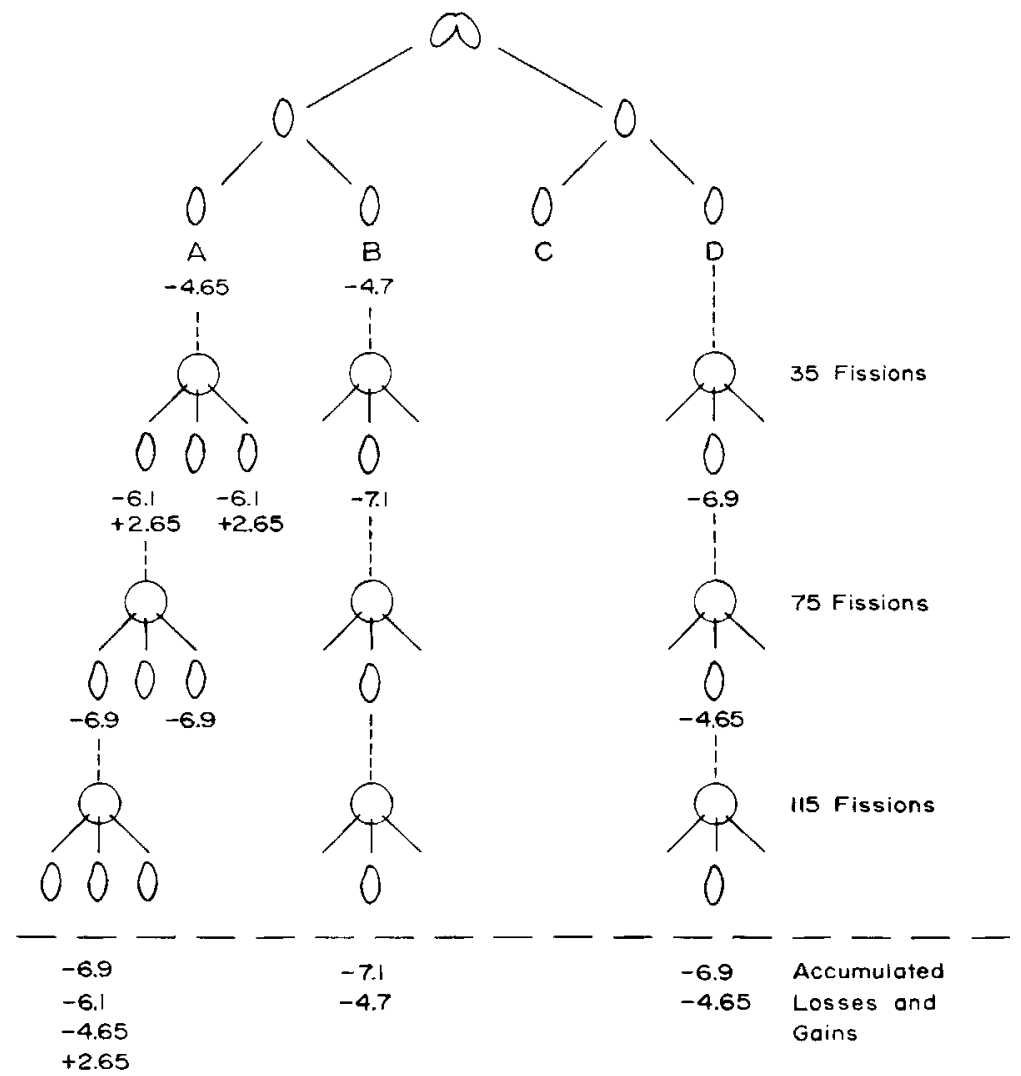

Fig. 4. Fragments containing $5 \mathrm{~S}$ gene clusters altered during "ageing" of $\mathrm{D} \times \mathrm{D} / 1$ caryonides. Caryonides A, B, and D were serially cloned at 35, 75, and 115 fissions. At each time point three or more single cells were isolated from a tubed population. All three subclones were analyzed at each time point for caryonide A. Only one subclone was analyzed at each time point for caryonides B and D. Losses of specific fragments $(7.1,6.9,6.1,4.7$, and $4.65 \mathrm{~kb}$ ) are indicated on the cell pedigree for specific subclones where loss was first noted. Gain of the $2.65-\mathrm{kb}$ fragment was first noted in two of the subclones of caryonide A at 35 fissions. Once a particular alteration occurs in a cell line, it is seen in all the descendants of that cell. The accumulated losses and gains of specific fragments are shown for each caryonide at the bottom of the diagram. 
cell isolations were made from one of the caryonidal lineages for $31 \mathrm{~A}, 31 \mathrm{~B}$, and 31D. MAC DNA was prepared from populations of cells grown for about 15-20 fissions from each of three subclones isolated at each time interval for the $31 \mathrm{~A}$ caryonide. Only one subclone at each time point was used for making MAC DNA for caryonides 31B and 31D.

The results of this experiment are summarized in Figure 4, which shows the presence $(+)$ or absence $(-)$ of fragments of particular sizes in subclones of increasing age derived from caryonides $31 \mathrm{~A}, 31 \mathrm{~B}$, and 31D. Most fragments were present in all subclones of the caryonides. Figure 4 focuses on the alterations that occur during vegetative replication. Two kinds of changes should be noted. First, certain fragments disappear at particular fissions in particular caryonides: the 6.1-kb fragment is absent from two of the A subclones at 35 fissions; the $6.9-\mathrm{kb}$ fragment is absent from caryonide $D$ at 35 fissions and from two of the $A$ subclones at 75 fissions; the 7.1-kb fragment is absent from caryonide B at 35 fissions; the $4.65-\mathrm{kb}$ fragment is absent from caryonide $\mathrm{A}$ by the first fission and from caryonide $\mathrm{D}$ at 75 fissions; and the 4.7-kb fragment is absent from caryonide B by the first fission. Secondly, a new fragment $(2.65 \mathrm{~kb})$ appears by 35 fissions in the $31 \mathrm{~A}$ series but has not yet appeared in the $31 \mathrm{~B}$ or $31 \mathrm{D}$ series. This fragment is one that is found in four of the six old cell clones.

There are features seen here which are characteristic of the phenomenon of phenotypic assortment. The first feature is stability. Once a particular "loss" or "gain" of a fragment occurs, the loss or gain is stable in subsequent replications. Thus, all subclones at further time points behave in a similar manner with regard to the loss or gain of the fragment. For example, in the 31A series, all subclones have lost the $6.1-\mathrm{kb}$ fragment and gained the $2.65-\mathrm{kb}$ fragment by 75 fissions (although no cause or effect is implied between these two fragment sizes). Further sampling at 115 fissions shows the maintenance of the loss and gain. Thus, once an alteration occurs, it is stably maintained.

A second feature associated with phenotypic assortment is the behavior of members of a pair of allelic forms sorting out as alternatives. Certain pairs of fragments behave as alternatives in their pattern of loss. For example, the 6.9- and 7.1-kb pair are both present in the caryonides immediately following conjugation, but either the 6.9-kb fragment is lost (in 31A and 31D) or the 7.1-kb fragment is lost (in 31B). Similarly, the 4.7- and 4.65-kb fragments also show assortment-either immediately after conjugation (in $31 \mathrm{~A}$ and $31 \mathrm{~B}$ ) or not until 75 fissions (for 31D).

These results strengthen the case for alteration of the fragment pattern of $5 \mathrm{~S}$ gene clusters occurring as a function of macronuclear replication. However, once the vegetative alteration occurs, it is apparently stable in a manner reminiscent of the stability associated with phenotypic assortment. Are these alterations random in their occurrence?

Nonrandom losses and gains of fragments with $5 \mathrm{~S}$ gene clusters occur in cell clones. Of the 34-37 fragments that appeared in the newly formed MAC (Table 1), a total of 16 disappeared from among the MAC of the six old cell clones. Of the 16 fragments, 12 were common to MIC and MAC and four were MAC-limited. Most of the fragments show loss from more than one clone. In fact, seven of the fragments are lost from three, or more, of the old cell clones. Thus, the distribution of losses among the cell clones is distinctly nonrandom (Fig. 5a). 
(a)
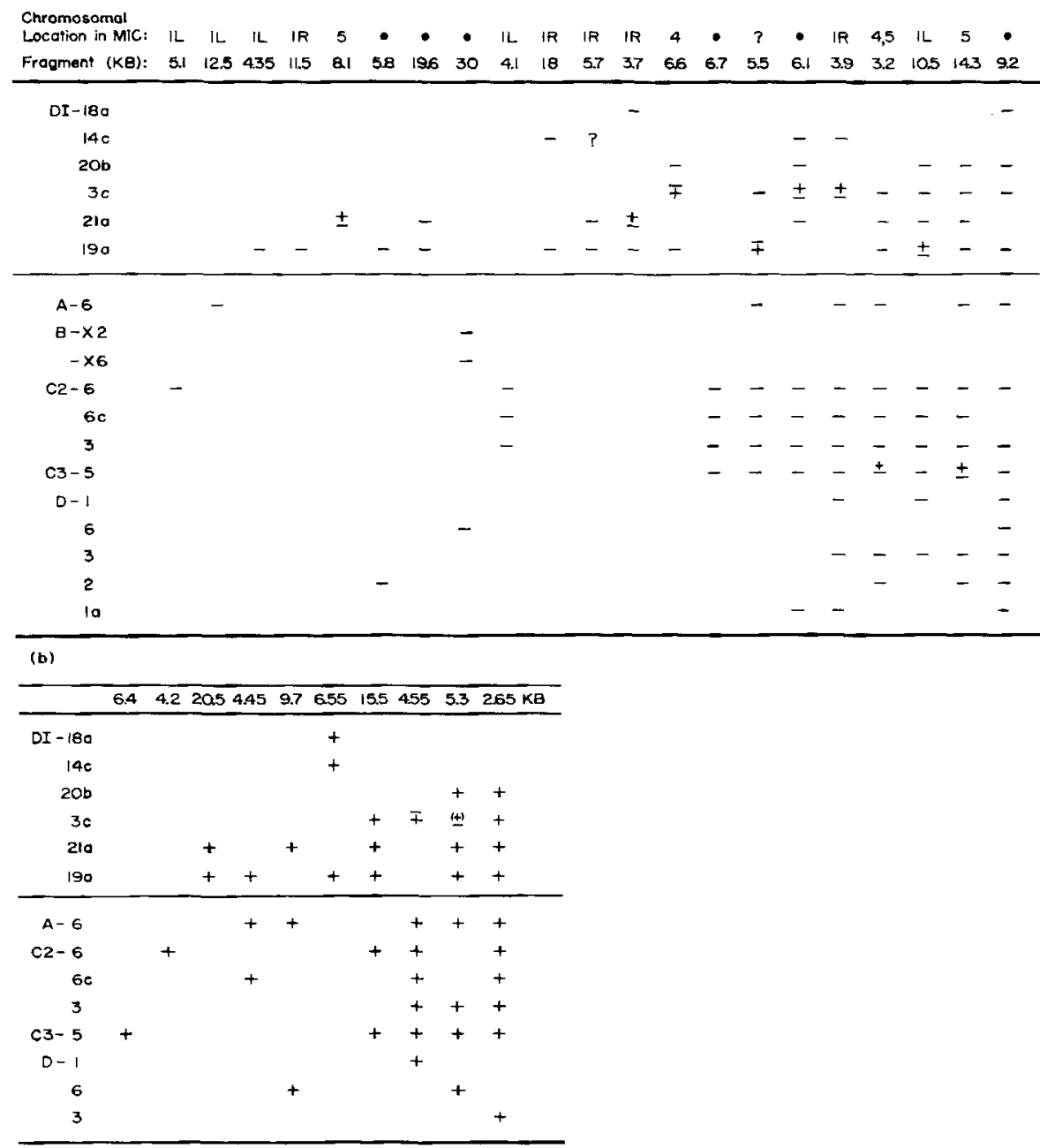

Fig. 5. Losses (a) and gains (b) of fragments bearing $5 S$ gene clusters in MAC DNA. At the top of each part are the data from the six $\mathrm{D} \times \mathrm{D} / 1$ old cell lines and their subclones. The bottom portion of each part includes data from the inbred strain clones (see Table 3 for complete clonal designations). The sizes of the fragments are identified by their kb (kilobases). In a, the chromosomal location in the MIC of certain fragments is indicated. MAC-limited fragments are indicated by a $\operatorname{dot}(\cdot)$. Subclonal variation is denoted by \pm or $\mp$ for losses and gains. \pm , presence in clone and absence in one or more of its subclones. $\mp$, absence in clone and presence in one or more of its subclones.

Six of the MIC/MAC fragments that disappear from the MAC of the old cell clones are located on chromosome 1 [17], of which five are on 1R. Deletion mapping permitted the following ordering of these fragments on $1 \mathrm{R}$, starting with the fragments most distal and moving inward toward the centromere: 3.7 and $3.9 \mathrm{~kb} ; 5.7 \mathrm{~kb} ; 11.5$ and $18 \mathrm{~kb}$ [17]. This same ordering is seen in the old clones with respect to loss of these fragments from the MAC (Fig. 5a). These observations suggest some form of progressive deletion affecting MAC chromosomal fragments. 
A total of eight new fragments are gained in the MAC from among the six old cell clones. Of these eight, five appear in more than one clone. Thus, the distribution of new fragments gained during MAC replication is also nonrandom among the cell clones (Fig. 5b). Whatever process results in the loss and gain of clusters from the MAC during vegetative growth must account for these nonrandom distributions of losses and gains among the old cell clones.

\section{Inbred Strain Clones}

Alteration of fragments with $5 \mathrm{~S}$ gene clusters also occurs during MAC replication in clones of some of the inbred strains. Table 3 shows that there is strain variation with respect to MAC alteration during vegetative growth. This variation is much greater than that expected on the basis of the few strain differences seen between MIC genomes [17]. Thus, most of the MAC variation seen here is probably epigenetic rather than genetic. Losses and gains of fragments are seen in

TABLE 3. Fragments With 5S Gene Clusters in the MAC After Vegetative Replication in Strains A, B, C2, $\mathrm{C} 3, \mathrm{D}$, and $\mathrm{D} / \mathbf{1}$

\begin{tabular}{|c|c|c|c|c|c|c|c|c|c|c|c|c|c|c|}
\hline \multirow{3}{*}{$\begin{array}{l}\text { Source } \\
\text { of DNA }\end{array}$} & \multirow{3}{*}{$\begin{array}{l}\text { Total No. } \\
\text { fragments }\end{array}$} & \multirow{3}{*}{$\begin{array}{c}\text { Total } \\
\mathbf{k b}\end{array}$} & \multicolumn{9}{|c|}{ Particular fragments } & \multicolumn{3}{|c|}{ No. of remaining fragments ${ }^{a}$} \\
\hline & & & \multicolumn{3}{|c|}{$\begin{array}{l}\text { MIC/MAC } \\
\text { fragments } \\
\end{array}$} & \multicolumn{4}{|c|}{$\begin{array}{l}\text { MAC-limited } \\
\text { fragments }\end{array}$} & & \multirow{2}{*}{6.1} & \multirow{2}{*}{$\begin{array}{l}\text { MIC/MAC } \\
\text { fragments }\end{array}$} & \multirow{2}{*}{$\begin{array}{c}\text { MAC- } \\
\text { limited } \\
\text { fragments }\end{array}$} & \multirow{2}{*}{$\begin{array}{c}\text { MAC fragments } \\
\text { gained } \\
\text { during aging }\end{array}$} \\
\hline & & & 10.5 & 4.7 & 4.65 & 9.7 & 9.27 & 7.8 & 7.1 & 6.96 & & & & \\
\hline A-17686 & 34 & 306.2 & + & + & - & + & - & - & + & - & + & 20 & $5^{b}$ & 4 \\
\hline B-2079X2 & 33 & 286.8 & + & + & - & - & - & + & + & - & - & 24 & $4^{\mathrm{c}}$ & 0 \\
\hline B-2079X6 & 33 & 286.7 & + & - & + & - & - & + & + & - & - & 24 & $4^{c}$ & 0 \\
\hline B-18684b & 34 & 321.9 & + & - & - & - & - & + & - & + & + & 25 & 5 & 0 \\
\hline B-18684 & 35 & 326.6 & + & + & - & - & - & + & - & + & + & 25 & 5 & 0 \\
\hline B- $18687 \mathrm{~N}$ & 35 & 326.6 & + & + & - & - & - & + & - & + & + & 25 & 5 & 0 \\
\hline B-18687B & 35 & 326.6 & + & + & - & - & - & + & - & + & + & 25 & 5 & 0 \\
\hline B-7B-1 ${ }^{\mathrm{d}}$ & 35 & 326.6 & + & + & - & - & - & + & - & + & + & 25 & 5 & 0 \\
\hline B-7B-2 & 35 & 326.6 & + & + & - & - & - & + & - & + & + & 25 & 5 & 0 \\
\hline B-7B-3 & 35 & 326.6 & + & + & - & - & - & + & - & + & + & 25 & 5 & 0 \\
\hline C2-3686 & 29 & 289.6 & - & - & + & - & - & - & + & + & - & 19 & $3^{\mathrm{e}}$ & 4 \\
\hline $\mathrm{C} 2-3686 \mathrm{c}$ & 30 & 285.3 & - & - & + & - & + & - & - & + & - & 20 & $4^{f}$ & 3 \\
\hline$C 2-4683$ & 29 & 277.0 & - & - & + & - & - & - & - & + & - & 20 & $4^{\mathrm{f}}$ & 3 \\
\hline C3-3685 & 34 & 320.5 & - & + & - & - & - & - & - & + & - & 23 & $4^{\mathrm{f}}$ & 5 \\
\hline$C 3-5 a^{d}$ & 33 & 317.3 & - & + & - & - & - & - & - & + & - & 22 & $4^{\mathrm{f}}$ & 5 \\
\hline C3-5b & 32 & 303.0 & - & + & - & - & - & - & - & + & - & 21 & $4^{f}$ & 5 \\
\hline C3-5c & 33 & 317.3 & - & + & - & - & - & - & - & + & - & 22 & $4^{f}$ & 5 \\
\hline D-25771 & 32 & 304.3 & - & - & - & - & - & - & - & + & + & 24 & 5 & 1 \\
\hline D-25776 & 35 & 304.0 & + & + & - & + & - & - & + & - & + & 25 & $4^{c}$ & 1 \\
\hline D-25773 & 31 & 289.6 & - & + & - & - & - & - & - & + & + & 22 & 5 & 1 \\
\hline D-25772 & 31 & 295.5 & + & + & - & - & - & - & - & + & + & 23 & $4^{g}$ & 0 \\
\hline D-25771a & 32 & 309.0 & + & + & - & - & - & - & + & - & - & 24 & 5 & 0 \\
\hline D-25772a & 34 & 318.8 & + & + & - & - & - & - & - & + & + & 25 & 5 & 0 \\
\hline $\mathrm{D} / 1\left(\mathrm{I}_{1}\right)-5771$ & 33 & 314.3 & + & - & - & - & - & - & + & - & + & 25 & 5 & 0 \\
\hline
\end{tabular}

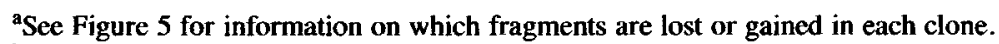

'Includes the MAC-limited 30-, 28-, 19.6-, 6.7-, and 5.8-kb fragments.

'Missing the MAC-limited 30-kb fragment.

${ }^{\mathrm{d}}$ Subcloned at approximately 2000 fissions.

${ }^{\text {e }}$ Missing the 6.7-, 5.8-kb fragments.

${ }^{f}$ Missing the MAC-limited 6.7-kb fragment.

gMissing the 5.8-kb fragment. 
strains $A, C 2, C 3$, and D, and, again, no obvious relationship is observed with respect to the sizes of the fragments lost or gained. Moreover, most of the fragments are the same ones as those lost and gained in the $\mathrm{D} \times \mathrm{D} / 1$ cell clones (see Fig. 5a,b). Among the D strain clones, the one with the least alterations (D25772a) is the clone that was frozen and had undergone many fewer fissions than the other clones. The one $\mathrm{D} / 1$ clone sampled was also frozen and does not show vegetative alteration. $\mathrm{C} 3-$ 3685 was subcloned. Additional losses of fragments were seen in the subclones, although the overall pattern of fragments was similar to the original clone.

Few alterations occur in the MACs of B strain clones. Losses of two fragments are seen in the 2079 pair of clones (derived by genomic exclusion), but no new fragments appeared. In the 1868 set only one fragment is lost in one out of four of the clones and no new fragments are gained in any of the clones, despite the fact that some of these clones were 2,000 fissions old and that one, or more, losses of fragments were seen in the MICs of these same clones [17]. B-18687B had a deletion of $1 R$. However, its MAC appears to have retained all fragments, suggesting stability during MAC replication. All three subclones of B-18687B have a pattern of fragments identical to each other and to 7B, further supporting the idea that the MAC in strain $\mathrm{B}$ is unusually stable during vegetative growth compared to the MAC of other strains.

\section{DISCUSSION}

The organization of the 5S rRNA genes in the MIC and MAC genomes is similar in that the genes are arranged in several tandem arrays of alternating transcribed and spacer sequences. Moreover, the number of clusters on EcoRI fragments is similar. Most clusters are found in both the MIC and newly formed MAC genomes, a few being MIC-limited and a few MAC-limited. The number of copies of the $5 \mathrm{~S}$ genes may be the same in MIC or MAC [23] or the copy number may increase by one-third during development of the MAC [17]. During replication of the MAC about half the fragments bearing $5 \mathrm{~S}$ gene clusters may disappear, and $5 \mathrm{~S}$ gene clusters on new EcoRI fragments that differ in size from those present in the MIC or newly formed MAC appear. These alterations occur in all strains except strain B, which is much more resistant to vegetative rearrangement. An altered fragment is stable vegetatively but shows clonal variation.

The alterations in fragment size seen in the MAC appear to occur in two stages of the life cycle of Tetrahymena. The first stage occurs during conjugation when the MAC develops from the MIC. The second stage occurs during vegetative growth when DNA replication occurs in the MAC, and daughter molecules are distributed "amitotically" to daughter nuclei.

During development of the MAC from the MIC, most clusters of 5S genes appear to be conserved on fragments similar in size to those in the MIC. Only a few rearrangements are seen with the disappearance of a few MIC-limited fragments and the appearance of a few clusters on EcoRI fragments new in size. The same rearrangements are seen in the MACs of all four caryonides of a mating pair, and very few differences are seen between pairs. Moreover, most of the same rearrangements are seen in the newly formed MACs of different inbred strains [17]. Thus, conservatism and nonrandomness characterize the process which leads to the alterations that occur with the development of the MAC from the MIC during conjugation. 
More extensive alterations occur in the MACs of most strains as they replicate during vegetative growth. Clonal variation is seen; yet, even here, there appear to be constraints, with stability and nonrandomness characterizing the process. Losses and gains of fragments with $5 \mathrm{~S}$ gene clusters occur during clonal propagation of a cell line. The process begins by 35 fissions following conjugation, but once an alteration occurs, it is stably propagated. This conclusion is reached by examining the behavior of the subclones of caryonides temporally, as measured in fissions. It is reinforced by the behavior of the subclones of the old clones. Different constellations of losses and gains occur in different cell lineages, although multiple occurrences are seen for particular losses and gains. Vegetative losses and gains of fragments with $5 \mathrm{~S}$ gene clusters occur during MAC replication in most strains, including the hybrid strain D $\times \mathrm{D} / 1$, the one most carefully studied in this report. The inbred B strain stands out as exceptionally resistant to vegetative alteration. There are known strain differences in the stability of the $M I C$ during vegetative growth. In certain genotypes, MIC loss may occur as early as 100-200 fissions, while in other genotypes loss is usually not observed before 1,000, or more, fissions [29]. That the MIC ages is an old observation [30]. Moreover, it has been known for some time that MIC instability leads to loss of fertility in crosses and irregularities in genetic transmission [31]. The B strain has one of those genotypes in which the MIC is most stable. Our observations suggest that strain differences also occur with respect to the stability of the MAC. The B strain genotype appears to result in a MAC that is also stable during vegetative growth.

The two-stage character to $\mathrm{MAC}$ alterations for the $5 \mathrm{~S}$ gene clusters seems to follow generally what has been observed previously for MAC differentiation involving other characters. A two-step process has been described: (a)"determination"during MAC formation (or at particular fissions following conjugation); (b) "phenotypic assortment"-during MAC replication.

Determination can be defined as the particular molecular event that leads to the setting up of a "heterogeneous" MAC, usually during its formation. A heterogeneous MAC results whenever a heterozygote is involved. It also occurs in cells homozygous at the mating type locus that are selfers-where the MAC contains units differentially determined for more than one mating type [32]. When determination occurs during anlagen formation (MAC development), it is subject to environmental influences such as temperature [32], starvation [33], and the concentration of particular ions [34].

Phenotypic assortment is seen as the resolution of MAC heterogeneity: the sorting out of one of the two allelic forms from a heterozygote or a single mating type from a selfer. The kinetics of the process reflect the total number of MAC units and has led to estimates of 45 copies for each gene in the Gl MAC [13]. It is a process remarkable for its lack of response to environmental influences or assaults. It can even occur in the complete absence of expression of a particular gene [13]. Once phenotypic assortment occurs, the cell line expressing one allele, or one mating type, is stable and irreversibly differentiated for that particular type.

Few losses and gains of fragments containing $5 \mathrm{~S}$ gene clusters appear to be seen immediately after conjugation. Many more may be seen after several hundred fissions in cell clones. If the process by which these alterations occur is equated to "determination," then some alterations must occur before the new MAC replicates its DNA content to $45 \mathrm{C}$, and some after. All copies of a particular altered DNA sequence would only be alike if the alteration occurred before DNA replication in the new 
MAC. Such an alteration would be visible immediately. To account for an alteration seen only after vegetative growth, the alteration in the MAC must occur during replication or after the DNA content has increased to 45C. If it occurred in one of the 45 copies of the DNA sequence, a heterogenous MAC would result. Phenotypic assortment would permit visualization of the new phenotype. A single copy of the altered DNA sequence might increase in number as a result of MAC replication and asymmetric distribution of the copies to a daughter MAC. Eventually a daughter MAC might be produced that contained all 45 copies of the altered sequence. The new phenotype would thus be expected to be completely stable in all the descendants of this MAC once homogeneity had been reached. It is in this context, then, that a loss or gain of a fragment with a $5 \mathrm{~S}$ gene cluster would be stable. Similar observations have been made for other DNA sequences, ones normally eliminated from the MIC that persist in the MAC [35].

At the molecular level, what kinds of processes could lead to the alterations in the 5S gene clusters that we are seeing in the MAC? Processes identified as occurring in the MAC during its development following conjugation are the following: fragmentation of the chromosomes [6,36]; addition of $\mathrm{C}_{4} \mathrm{~A}_{2}$ repeats to the ends of the MAC fragments [6]; interstitial deletions [10,11]; elimination and/or underreplication of MIC sequences [7-9,35,36]; methylation of adenines [37,38,39]; gene amplification [5]; and changes in chromosomal proteins [12]. The 5S gene alterations are seen as a change in the size of EcoRI fragments containing the tandem arrays of $5 \mathrm{~S}$ genes. A size change could result from any number of possible events occurring: (a) at the EcoRI site itself with consequent loss or gain of a functional site, (b) within the region of sequences flanking the 5S gene cluster as a result of deletions or additions, or (c) within the $5 \mathrm{~S}$ gene cluster itself as a result of crossing over within or between clusters. If the same type of molecular event is responsible for the alterations seen during formation of the MAC as well as during its replication in vegetative growth (ie, the determinative event is the same), then only some of the processes identified so far as occurring during MAC development, or as potentially occurring, may be relevant here. Possible relevant processes include methylation of adenines, fragmentation, interstitial deletions, and crossing over.

Methylation of adenines at the EcoRI site is probably not involved. In a study comparing MIC and MAC DNA, approximately the same total number as well as about the same number of MIC and MAC-limited fragments with 5S gene clusters was observed using either EcoRI or Hind III to cut the DNA [23]. Hind III, like EcoRI, cuts at sites external to the $5 \mathrm{~S}$ gene cluster, but Hind III, which cuts at AAGCTT, is insensitive to methylation, since the in vivo methylation site contains the bases $5^{\prime}$-NAT [38]. We observed clonal variation in fragment size with other restriction enzymes, including Hind III, that cut at sites external to the $5 \mathrm{~S}$ gene cluster (data not shown). Therefore, the clonal differences do not appear to be due to differences in methylation.

Fragmentation of chromosomes is probably not involved in generating size differences in fragments with 5S gene clusters. According to Pederson et al [23], 5S gene-containing MAC-limited fragments generated during MAC development are not sensitive to the exonuclease Ba131, suggesting that these $5 \mathrm{~S}$ gene clusters are not near the ends of the MAC chromosomal fragments. There is, however, the observation that fragments that map to $1 \mathrm{R}$ in the MIC show a nonrandom distribution of loss during vegetative growth in the MAC of the old cell clones. The ordering of losses is 
reminiscent of the deletion map for $1 \mathrm{R}$ in the $\mathrm{MIC}$, with the smallest deletions speculated as occurring at the telomere [17].

The most likely processes accounting for the MAC 5S gene alterations are interstitial deletions of MAC sequences flanking the clusters or some form of crossing over between $5 \mathrm{~S}$ genes either within the same cluster or between clusters. MAC deletions have been described before for other types of sequences [10,11]. The observation that the $\mathrm{kb}$ totals of the MAC $5 \mathrm{~S}$ fragments decrease could be interpreted in terms of deletions, either of the flanks or within the cluster. Crossing over as a relevant process has been suggested before [40] but not documented experimentally. With crossing over between $5 \mathrm{~S}$ clusters, we would expect to see new fragment sizes that relate to the sizes of the old fragments, but this relationship has not been seen. Experiments are in progress testing whether deletions within a flank or crossing over within a cluster is involved in bringing about the alterations in fragment size seen for the $5 \mathrm{~S}$ gene clusters.

\section{CONCLUSIONS}

The 5S rRNA genes are organized similarly in the MIC and MAC genomes: In both nuclei the genes are arranged in several tandem arrays of alternating transcribed and spacer sequences. The number of clusters on EcoRI fragments is similar, although the number of copies of the $5 \mathrm{~S}$ genes remains the same or increases by one-third in the newly formed MAC genome. Alterations in fragment size in the MAC appear to occur at two stages of the life cycle of Tetrahymena. The first stage occurs during conjugation when the MAC develops from the MIC. At this stage the alterations are modest, most clusters being found on fragments identical in size to those in the MIC. The second stage occurs during vegetative growth when DNA replication occurs in the MAC and daughter molecules are distributed "amitotically" to daughter nuclei. At this time about half the fragments bearing $5 \mathrm{~S}$ gene clusters disappear in different cell lines, and new fragments with $5 \mathrm{~S}$ genes appear that differ in size from those fragments present in the MIC or newly formed MAC. The vegetative alterations occur in the MAC of all except the B strain and are stable, but show clonal variation with respect to which losses and gains of fragments with $5 \mathrm{~S}$ gene clusters are seen. These observations can be interpreted in terms of the phenomena of "determination" and "phenotypic assortment," two steps that occur generally with MAC differentiation. The determinative event that leads to alterations in the 5S gene clusters could occur before the MAC DNA content reaches 45C during MAC development, or after. The resulting MAC heterogeneity would then be resolved with phenotypic assortment. The most plausible molecular interpretations of the determinative event are deletion/ splicing of sequences flanking the $5 \mathrm{~S}$ gene clusters or crossing over within a cluster or between clusters.

\section{ACKNOWLEDGMENTS}

This research was supported by research grants PCM-8300502 from the National Sciences Foundation and GM-33112 from the National Institute of General Medical Sciences, U.S. Public Health Service. T.C. White was supported in part by a National Institute of Health predoctoral training program and in part by a Rackham Fellowship and a Burton L. Baker Memorial Fellowship in Cancer Research from 
The University of Michigan. We thank David Pederson for sending us pDP5 and Almuth H. Tschunko for her drawing of Figures 1, 4, and 5.

\section{REFERENCES}

1. Marcu KB, Cooper MD: New views of the immunoglobulin heavy-chain switch. Nature 298:327$328,1982$.

2. Haber JE, Rogers DT: Transposition of a tandem duplication of yeast mating-type genes. Nature 296:768-770, 1982.

3. Borst P, Cross GAM: Molecular basis for typanosome antigenic variation. Cell 29:291-303, 1982.

4. Calabretta B, Robertson DL, Barrera-Saldana HA, Lambrou TP, Saunders GF: Genome instability in a region of human DNA enriched in Alu repeat sequences. Nature 296:219-225, 1982.

5. Yao MC, Blackburn E, Gall JG: Amplification of the rRNA genes in Tetrahymena. Cold Spring Harbor Symp Quant Biol 43:1293-1296, 1979.

6. Yao MC, Yao CH: Repeated hexonucleotide C-C-C-C-A-A is present near free ends of macronuclear DNA of Tetrahymena. Proc Natl Acad Sci USA 78:7436-7439, 1981.

7. Yao MC: Elimination of specific DNA sequences from the somatic nucleus of the ciliate Tetrahymena. J Cell Biol 92:783-789, 1982.

8. Brunk CF, Tsao SGS, Diamond CH, Ohashi PS, Tsao NNG, Pearlman RE: Reorganization of unique and repetitive sequences during nuclear development in Tetrahymena thermophila. Biochem 60:847-853, 1982.

9. Iwamura Y, Sakai M, Muramatsu, M: Rearrangement of repeated DNA sequences during development of macronucleus in Tetrahymena thermophila. Nucleic Acids Res 10:4279-4291, 1982.

10. Callahan RC, Shalke G, Gorovsky MA: Developmental rearrangements associated with a single type of expressed $\alpha$-tubulin gene in Tetrahymena. Cell 36:441-446, 1984.

11. Yao MC, Choi J, Yokoyama S, Austerberry CF, Yao CH: DNA elimination in Tetrahymena: A developmental process involving extensive breakage and rejoining of DNA at defined ends. Cell 36:433-440, 1984.

12. Gorovsky MA: Genome organization and reorganization in Tetrahymena. Annu Rev Genet 14:203$239,1980$.

13. Nanney DL, Preparata RM: Genetic evidence concerning the structure of the Tetrahymena thermophila macronucleus. J Protozool 25:2-9, 1979.

14. Kimmel AR, Gorovsky MA: Numbers of 5S and tRNA genes in macro- and micronuclei of Tetrahymena pyriformis. Chromosoma 54:327-337, 1976.

15. Kimmel AR, Gorovsky MA: Organization of the 5S RNA genes in macro- and micronuclei of Tetrahymena pyriformis. Chromosoma 67:1-20, 1978.

16. Long EO, Dawid IB: Repeated genes in eukaryotes. Annu Rev Biochem 49:727-764, 1980.

17. Allen SL, Ervin PR, McLaren NC, Brand RE: The 5S ribosomal RNA gene clusters in Tetrahymena thermophila: Strain differences, chromosomal localization, and loss during micronuclear aging. Mol Gen Genet 197:244-253, 1984.

18. Selker, EU, Yanofsky C, Driftmier K, Metzenberg RL, Alzner-DeWeerd B, RajBhandary UL: Dispersed 5S RNA genes in N. crassa: Structure, expression and evolution. Cell 24:819-828, 1981.

19. Bruns PJ: Tetrahymena thermophila. Genetic Maps 2:178-181, 1982.

20. Allen SL, Lee PHT: The preparation of congenic strains of Tetrahymena. J Protozool 18:214-218, 1971 .

21. Bruns PJ, Mфller KM, Leick V: Magnetic purification of mating Tetrahymena. Carlsberg Res Commun 45:29-33, 1980.

22. Allen SL, White TC, Langmore JP, Swancutt MA: Highly purified micro- and macronuclei from Tetrahymena thermophila isolated by percoll gradients. J Protozool 30:21-30, 1983.

23. Pederson DS, Yao MC, Kimmel AR, Gorovsky MA: Sequence organization within and flanking clusters of 5S ribosomal RNA genes in Tetrahymena. Nucleic Acids Res 12:3003-3022, 1984.

24. Gunsalus RP, Zurawski G, Yanofsky C: Structural and functional analysis of cloned deoxyribonucleic acid containing the trpR-thr regions of the Escherichia coli chromosome. I Bacteriol 140: 106$113,1979$.

25. Maniatis T, Jeffrey A, Kleid KG: Nucleotide sequence of the rightward operator of phage $\lambda$. Proc Natl Acad Sci USA 72:1184-1188, 1975. 
26. Rigby PWJ, Dieckmann M, Rhodes C, Berg P: Labeling deoxyribonucleic acid to high specific activity in vitro by nick translation with DNA polymerase I. J Mol Biol 113:237-251, 1977.

27. Southern E: Detection of specific sequences among DNA fragments separated by gel electrophoresis. J Mol Biol 98:503-517, 1975.

28. Denhardt D: A membrane-filter technique for the detection of complementary DNA. Biochem Biophys Res Comm 23:641-652, 1966.

29. Nanney DL: Vegetative mutants and clonal senility in Tetrahymena. J Protozool 6:171-177, 1959.

30. Nanney DL: Inbreeding degeneration in Tetrahymena. Genetics 42:137-147, 1957.

31. Nanney DL: Irregular genetic transmission in Tetrahymena crosses. Genetics 48:737-744, 1963.

32. Orias E: Probable somatic DNA rearrangements in mating type determination in Tetrahymena thermophila: A review and a model. Dev Genet 2:185-202, 1981.

33. Orias E, Baum MP: Mating type differentiation in Tetrahymena thermophila: Strong influence of delayed refeeding of conjugating pairs. Dev Genet 4:145-158, 1984.

34. Orias E: Specific ion effects on mating type and rDNA differentiation in the Tetrahymena developing macronucleus. Personal communication, 1984.

35. White TC, Allen SL: Macronuclear persistence of sequences normally eliminated during development in Tetrahymena thermophila. Submitted to Dev Genet, 1985.

36. Yao MC: Ribosomal RNA gene amplification in Tetrahymena may be associated with chromosome breakage and DNA elimination. Cell 24:765-774, 1981.

37. Gorovsky MA, Hattman S, Pleger GL: $\left[{ }^{6} \mathrm{~N}\right]$ methyl adenine in the nuclear DNA of a eukaryote, Tetrahymena pyriformis. J Cell Biol 56:697-701, 1973.

38. Bromberg S, Pratt K, Hattman S: Sequence specificity of DNA adenine methylase in the protozoan Tetrahymena thermophila. J Bacteriol 150:993-996, 1982.

39. Blackburn EH, Pan WC, Johnson CC: Methylation of ribosomal RNA genes in the macronucleus of Tetrahymena thermophila. Nucleic Acids Res 11:5131-5145, 1983.

40. Orias E: Alternative interpretation of the molecular structure and somatic genetics of acid phosphatase-1 in Tetrahymena pyriformis. Biochem Genet 9:87-90, 1973. 